\title{
Variations in magnitude of reward and position reversal learning following septal lesions in the rat
}

\author{
WAIL A. BENGELLOUN, DEBORAH J. NELSON, JEFFREY M. GERTH, and WILLIAM W. BEATTY \\ North Dakota State University, Fargo, North Dakota 58102
}

\begin{abstract}
Two experiments examined the possibility that increased reactivity to positive reinforcement might contribute to the deficient performance on position reversal tasks by rats with septal lesions. Increasing the number of Noyes pellet rewards facilitated reversal learning by control subjects and by rats with septal lesions, but the magnitude of the impairment by the animals with lesions was not affected by the variation in quantity of reinforcement; regardless of the reward magnitude, rats with septal lesions exhibited impairments in performance that persisted for 10 reversals. Altering the quality of reinforcement also did not affect reversal performance by the animals with lesions.
\end{abstract}

Lesions of the septal area disrupt performance on a number of tasks which require the subject to abandon an initially prepotent response including passive avoidance behavior (e.g., McCleary, 1961; see Fried, 1972 for additional references), responding on DRL schedules (e.g., Braggio \& Ellen, 1974; Ellen, Wilson \& Powell, 1964) and reversal of a position habit (e.g., Donovick, 1968; Hamilton, Kelsey, \& Grossman, 1970; Schwartzbaum \& Donovick, 1968). Septal lesions also enhance responsiveness to a wide range of positive reinforcers including water (e.g., Harvey \& Hunt, 1965), sucrose (e.g., Beatty \& Schwartzbaum, 1968; Neill, Ross, \& Grossman, 1974), and Noyes pellets (Hothersall, Johnson, \& Colleen, 1970). Recent findings indicate that the exaggerated reaction to positive reinforcement that accompanies damage to the septum contributes to the deficit in performance of passive avoidance (Beatty, Beatty, O'Briant, Gregoire, \& Dahl, 1973; Gittelson, Donovick, \& Burright, 1969) and DRL behavior (Kelsey \& Grossman, 1971; Carlson, Standish, \& El-Wakil, Note 1).

In the present experiments, we evaluated the possibility that motivational changes might contribute to the deficits observed following septal lesions on position reversal learning. This possibility seemed worth assessing because deficits in position reversal after septal lesions are accompanied by more rapid performance on the task (Donovick, 1968; Schwartzbaum \& Donovick, 1968). If exaggerated responsiveness to positive reinforcement is a factor in the deficient position reversal learning of rats with septal lesions, then reducing the attractiveness of the reinforcer by reducing its quality or quantity would be expected to attenuate the magnitude of the deficit.

We thank Tom Vilberg, Jim Gange, Rusty Ridley, Joyce Stromme, and Jean Sapa for help in testing the animals and Peter Donovick and Richard Burright for helpful comments on the manuscript. Preparation of the manuscript was aided by NIH Grant HD 08206 to William W. Beatty. Address reprint requests to William W. Beatty, Department of Psy chology, North Dakota State University, Fargo, North Dakota 58102. W. A. Bengelloun is now at SUNY, Binghamton.

\section{EXPERIMENT I}

In this experiment, the effect of varying the quality of reinforcement by adulterating standard Noyes pellets with cellulose on reversal learning was studied. Reducing the attractiveness of the reinforcer in this way has been shown to reduce the deficit in passive avoidance behavior (Beatty et al., 1973) and DRL performance (Carlson et al., Note 1) in animals with septal lesions.

\section{Method}

Animals. The subjects were 17 naive male Holtzman rats that weighed $300-340 \mathrm{~g}$ at the start of the experiment. They were caged singly in an air-conditioned animal room that was illuminated from 0900 to 2100 . Behavioral tests occurred during the light portion of the diurnal cycle. The rats were assigned randomly to one of three groups: One group $(N=6)$ received bilateral septal lesions and were rewarded for correct choices with standard 45-mg Noyes pellets; a second group $(\mathrm{N}=6)$ sustained septal lesions and were rewarded for correct choices with $45-\mathrm{mg}$ pellets prepared by the P. J. Noyes Company so that they contained equal amounts by weight of cellulose and the standard formula; rats in the third group $(\mathrm{N}=5)$ received control operations and were rewarded with standard $45-\mathrm{mg}$ Noyes pellets. It was not possible to test control animals with the cellulose-adulterated reward because preliminary studies indicated that controls did not consistently eat these pellets.

All rats that sustained septal lesions in this and the subsequent experiment displayed hyperemotionality for a few days postoperatively, but overt signs of this reaction had dissipated before the maze tests began.

Surgery and histology. Bilateral lesions were produced stereotaxically by passing $2 \mathrm{~mA}$ dc for $15 \mathrm{sec}$ between the brain anode and a rectal cathode using procedures described elsewhere (Beatty et al., 1973). Control animals received either a scalp incision or were merely anesthetized. Histological analysis indicated that the lesions generally resembled those described in earlier studies from this laboratory (Beatty et al., 1973). The medial septal nucleus was completely destroyed in all cases and the lateral septal nuclei were extensively damaged, bilaterally in most instances. Damage to other structures including the fornix, the corpus callosum, the caudate patamen, the nucleus accumbens, and the overlying medial cortex, which was usually unilateral in nature, occurred to varying degrees in some subjects. However, neither the amount of damage to the septal 


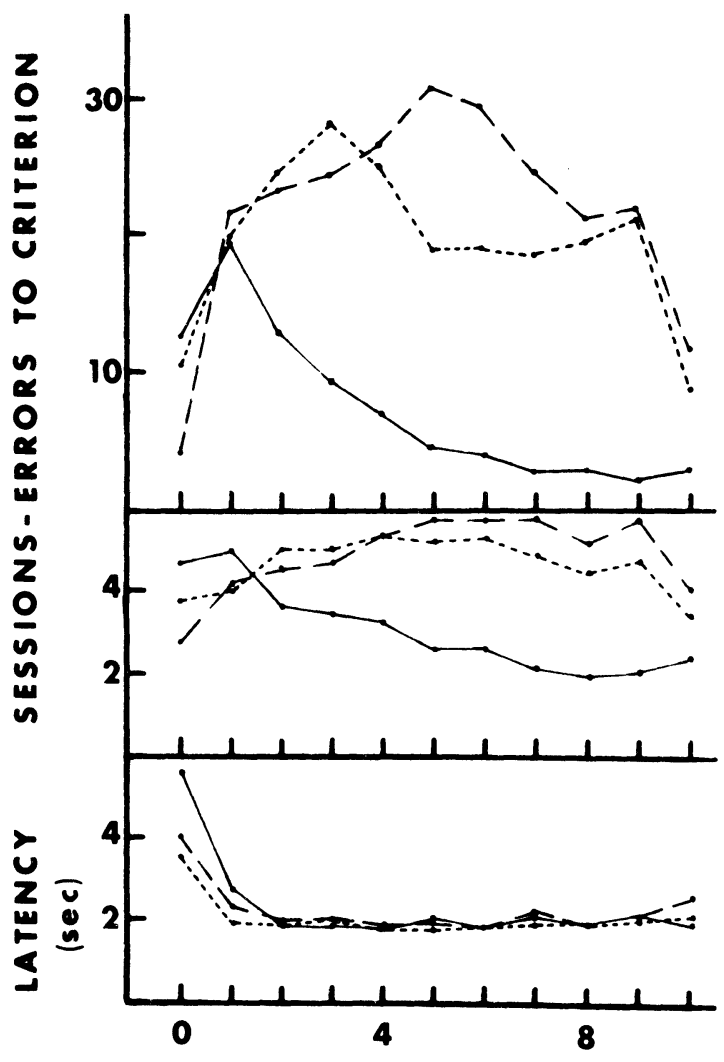

REVERSAL

Figure 1. Mean number of errors to criterion (upper panel) and sessions to criterion (middle panel) during OL (Reversal 0) and reversal learning in Experiment I. Rats in the control group (solid line) received standard Noyes pellets for correct choices. Performance by the septal group rewarded with regular Noyes pellets is indicated by dotted lines. Broken lines describe performance by rats with septal lesions reinforced with cellulose-adulterated pellets. Latency scores (lower panel) were computed by finding the median latency for each subject on each reversal and computing the group mean of individual subject median scores.

area nor to the structures outside of the septum was sytematically related to performance on any of the measures. This is not surprising since earlier work suggests that damage restricted to the medial septal nucleus is sufficient to impair reversal learning (Donovick, 1968; Hamilton et al., 1970).

Apparatus. A Y maze constructed of clear plastic and aluminum with a floor made of bronze welding rods was employed. Each arm of the maze, including the start arm, was $81.28 \times 10.16 \times 13.97 \mathrm{~cm}$ high, including a 50.80 -cm-long startor goalbox. A foodcup was mounted on the end wall of each goalbox $2.54 \mathrm{~cm}$ above the floor. Guillotine doors at the entrance to each goalbox or at the end of the startbox controlled access to these areas.

Procedure. Following a 2-week-long postoperative recovery period, the rats were placed on a restricted feeding schedule designed to maintain them at $85 \%$ of their free feeding weight. Water was freely available in the home cage. The deprivation regimen was initially based upon the animal's preoperative body weight and adjustments were made throughout the experiment to allow for growth by referring to growth curves for animals of this age and sex. In making these adjustments, no attempt was made to correct for differences in growth that have sometimes been observed between control rats and animals with septal lesions.

On the 1st day of pretraining, the rats were allowed to explore the maze for $10 \mathrm{~min}$ and consume six food pellets from each foodcup. On the 2 nd day, each rat was given six nonrewarded trials to test for position preferences; no animal chose either arm more than four times. On the next day, original learning (OL) began. During OL, animals that exhibited a position preference were rewarded for the choice opposite to their bias; for the remaining animals, the correct choice during OL was determined by a coin toss. Correct responses were rewarded with two $45-\mathrm{mg}$ Noyes pellets. On incorrect trials, the rat was confined in the empty goalbox for $10 \mathrm{sec}$. A noncorrection procedure was used throughout the experiment. Each daily session consisted of 15 trials with a 10 -sec ITI. Training on OL continued until the rat met a criterion of 13 of 15 correct choices for two consecutive sessions. On the following day, training on the first reversal began using identical procedures except that the correct choice was reversed. Each rat was trained on 10 such reversals. Throughout testing, the latency from the time the startbox door was raised until the rat activated a contact relay located $42.12 \mathrm{~cm}$ from the entrance to either goalbox was recorded on each trial.

\section{Results}

Figure 1 summarizes performance throughout the experiment. Analysis of the OL data revealed significant differences among groups on all measures $[\mathrm{F}(2,14)=$ $6.64,6.66,4.00, \mathrm{p}<.01, .01, .05$ for errors to criterion, sessions to criterion and latency, respectively). Subsequent analyses with $t$ tests revealed that rats with septal lesions rewarded with cellulose-adulterated pellets met the learning criterion in fewer sessions and made fewer errors than either of the other two groups $(p<.05)$. Controls and animals with septal lesions that were rewarded with standard Noyes pellets did not differ significantly on either the errors or sessions to criterion measures. However, animals with septal lesions receiving standard Noyes pellets achieved shorter latency scores than controls during OL $(p<.02)$. The group with septal lesions that was rewarded with cellulose-adulterated pellets did not differ reliably from either of the other groups on the latency measure during OL.

Analysis of the reversal data revealed significant differences among groups on both the errors and sessions to criterion measures $[\mathrm{F}(2,14)=13.37$ and 12.43 , both $\mathrm{p}<.001$, respectively] but no significant difference among groups on the latency measure $(F<1)$. Subsequent $t$ tests demonstrated that both groups of rats with septal lesions made significantly more errors and required significantly more sessions to meet criterion than controls (all $\mathrm{p}<.01$ ). However, there was no significant difference between the two groups with septal lesions on either measure. Although the analysis of variance failed to reveal a significant Groups by Reversals interaction, it should be noted that differences between septal and control groups were not clear cut until the third reversal on either the errors or the sessions to criterion measures. Performance by both 
groups of animals with lesions remained inferior to that of controls thereafter.

The persistence of the impairment in reversal performance among the lesion groups was also apparent if one examines the minimum number of reversals required to meet the learning criterion in two sessions (the minimum number of sessions to criterion). All five of the control animals attained this level of performance (median number of reversals to the first two-session reversal $=6$ ), while only one of the 12 lesioned subjects reached this level of performance within 10 reversals.

During reversal learning, there was no significant difference among groups on the latency measure.

\section{EXPERIMENT II}

Reducing the quality of reinforcement did not improve the reversal learning of rats with septal lesions, although it did facilitate acquisition of the original position habit. In this experiment, we studied the effects of varying magnitude of reward on reversal performance by varying the number of pellets given for a correct choice.

\section{Method}

Twenty-eight naive male Holtzman rats that weighed 295-342 $\mathrm{g}$ at the start of the experiment were assigned at random to one of four groups: septal lesion, one pellet reward $(N=7)$; septal lesion, five pellets reward $(N=7)$; control operation, one pellet reward $(\mathrm{N}=6)$; control operation, five pellets reward $(\mathrm{N}=8)$. Housing and surgical procedures were the same as in Experiment I. The Y maze apparatus was modified by mounting a drinking spout on the back wall of the startbox. The training procedure was the same as in Experiment I, except that the rat was allowed ad-lib access to water in the startbox before the beginning of each trial. This procedural change was made because we were concerned that animals in the five-pellet groups might experience more dryness of the mouth which might have differentially affected performance. Consequently, the ITI did vary, depending on the rat's water consumption in the startbox, but rarely exceeded $20 \mathrm{sec}$. The animals received either one or five Noyes pellets $(45 \mathrm{mg}$, standard formula) for each correct choice.

\section{Results}

Figure 2 summarizes performance throughout the experiment. During OL, neither magnitude of reward nor septal lesions significantly affected performance on either the errors or sessions to criterion measure. In contrast to OL, both magnitude of reward and septal lesions affected reversal learning. Over the 10 reversals studied, animals rewarded with five pellets met the reversal learning criterion in fewer sessions $[F(1,24)=23.38, \mathrm{p}<.001]$ and made fewer errors $[F(1,24)=19.26, \mathrm{p}<.001]$ than animals rewarded with one pellet. Septal lesions increased the number of sessions to criterion $[F(1,24)=73.02, p<.001]$ and the number of errors $[\mathrm{F}(1,24)=122.83, \mathrm{p}<.001]$, but there was no suggestion of a Lesion by Magnitude of Reward or a Lesion by Magnitude of Reward by Reversals interaction on either measure. The Lesion by

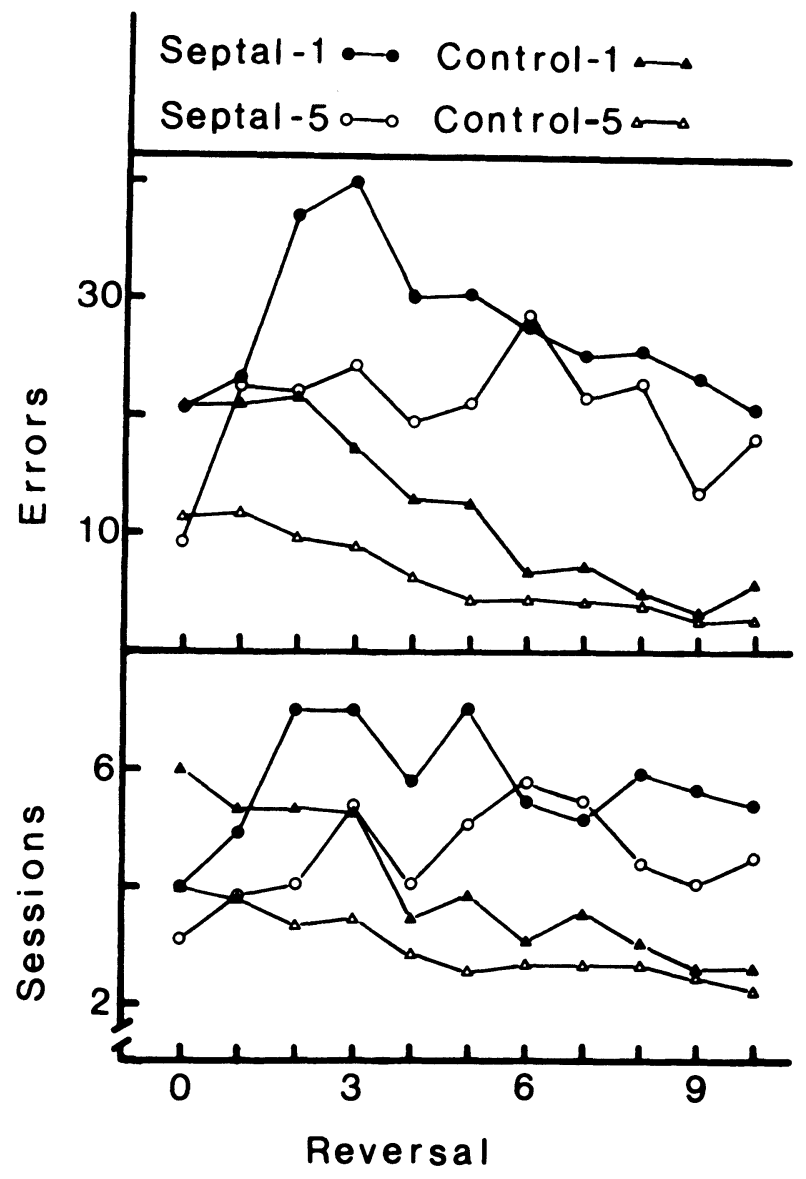

Figure 2. Mean number of errors to criterion and sessions to criterion during OL (Reversal 0) and reversal learning in Experiment II by groups of rats with septal lesions or control operations rewarded with one or five Noyes pellets.

Reversals interaction attained significance on the sessions to criterion analysis $[F(9,216)=2.87, p<.05]$, but not on the errors to criterion measure. Subsequent analysis with $t$ tests of the Lesion by Reversal interaction indicated that differences between septal and control groups on the sessions to criterion measure attained significance by the 2 nd reversal and persisted through the 10 th reversal.

The persistence of the reversal deficit was also reflected in the minimum number of reversals required to the first two-session reversal. All of the eight subjects in the control five-pellet group and five of the six subjects in the control one-pellet group attained this level of performance (median number reversals to the first two-session reversal $=5.5$ for the control five-pellet group and eight for the control one-pellet group, $U=11$, n.s.). In contrast, only 1 of the 14 subjects with septal lesions achieved a two-session reversal during the 10 reversals tested.

Response latencies were very similar to those observed in the first experiment (see lower parel of Figure 1). During OL, animals with septal lesions responded more 
rapidly than controls [mean latency: septal groups $=3.3 \mathrm{sec}$, control groups $=8.4 \mathrm{sec}$; $\mathrm{F}(1,24)=5.77, \mathrm{p}<.05]$, but there was no effect of magnitude of reward on latency scores. As training continued during the reversal phase of the study, response latencies for all groups rapidly stabilized at approximately $2 \mathrm{sec}$. During reversal learning, neither septal lesions nor magnitude of reward significantly influenced latency scores.

\section{Discussion}

Variations in the magnitude of reward failed to affect the magnitude of the deficit in reversal learning in animals with septal lesions. Reducing the quality of reward with cellulose facilitated the acquisition of the original position habit in rats with septal lesions but did not affect their reversal performance. Increasing the number of pellets for correct choices improved reversal learning by both septal and control groups by about the same amount. Finally, septal lesions shortened response latencies during $\mathrm{OL}$ in both experiments but did not affect latencies during reversal learning in either experiment. Taken together, these results provide no support for the hypothesis that increased responsiveness to the incentive properties of positive reinforcements is an important factor in the deficient position reversal learning that results from septal lesions.

Previous findings indicate that increased responsiveness to the attractive properties of positive reinforcements contributes to the deficient performance of rats with septal lesions on passive avoidance and DRL tasks. Kelsey and Grossman (1971) observed that the deficit in DRL performance arises principally because rats with septal lesions anticipate the availability of the next reinforcement, not because they make abnormally high numbers of perseverative responses. Carlson et al. (Note 1) observed that reducing the quality of reward by diluting the food pellets with cellulose eliminated the impairment in DRL performance in mice with septal lesions. A similar manipulation of reward quality attenuated the deficit in retention of passive avoidance behavior by rats with septal lesions (Beatty et al., 1973). Since the method of manipulating reward quality used by Carlson et al. (Note 1) and Beatty et al. (1973) is very similar to the one used in the present study, it seems unlikely that our failure to observe an effect of this variable on reversal learning by rats with septal lesions occurred because of an inappropriate manipulation of the reward quality variable. The fact that rats with septal lesions rewarded with cellulose pellets learned the original position habit more rapidly than the other groups buttresses this assertion.

While it is not clear why manipulations that presumably affect the attractiveness of the reward should influence the behavior of animals with septal lesions on passive avoidance and DRL tasks but not on position reversal learning, it is important to recognize that the availability of a reinforcer to which animals with septal lesions overract by increased consumption or more rapid approach behavior is neither necessary nor sufficient for the development of deficits in performance on DRL, passive avoidance, or reversal learning tasks. Septal lesions impair passive avoidance in the absence of either deprivation or positive reinforcement (Beatty et al., 1973; Slotnick and Jarvik, 1966) and reducing the quality of reward affects only the retention of passive avoidance behavior by rats with septal lesions; deficits in the acquisition of passive avoidance are not influenced by this manipulation (Beatty et al., 1973). The usually robust deficits in DRL performance by animals with septal lesions which occur when the reinforcement schedule is abruptly shifted from CRF to a relatively stringent DRL contingency can be alleviated by gradually increasing the temporal requirements of the DRL contingency (Caplan \& Stamm, 1967; Harvey \& Hunt, 1965), signaling the availability of reinforcement with a visual cue (Ellen \& Butter, 1969), enhancing proprioceptive feedback (Braggio \& Ellen, 1974) or introducing other stimuli into the test environment which promote the development of adjunctive behaviors (Slonaker \& Hothersall, 1972). The appearance of deficits in discrimination reversal following septal lesions is also highly dependent on the specific stimuli in the test situation. Thus septal lesions produce deficits in position reversal learning, which may be transient (e.g., Donovick, 1968; Scwhartzbaum \& Donovick, 1968) or persistent (Srebro \& Divac, 1972 and the present experiments), and in the reversal of a kinesthetic discrimination (Gittelson \& Donovick, 1968), but do not impair the reversal of a brightness discrimination (Schwartzbaum \& Donovick, 1968). Moreover, the addition of visual cues to the test situation attenuates deficits in retention of position reversal learning sets that otherwise result from septal lesions (Srebro, 1974).

The fact that the performance of animals with septal lesions on DRL and position reversal tasks can be dramatically improved by introducing additional stimuli which predict the availability of reinforcement (e.g., Ellen \& Butter, 1969; Srebro, 1974) has led several workers (see, e.g., Fried, 1972) to propose that septal lesions impair the ability to utilize response-produced cues. While this interpretation may be in part correct, it is also clear that the performance of animals with septal lesions may be grossly abnormal in learning tasks where exteroceptive stimuli provide the discriminative cues. Depending on the specific test procedures, septal lesions may impair (e.g., Schwartzbaum, Kellicutt, Spieth, \& Thompson, 1964; Chin, Donovick, \& Burright, Note 2) or facilitate (Gomer \& Goldstein, 1974) performance. Furthermore, septal lesions can exaggerate reactivity to a very broad range of external stimuli including light (Schwartzbaum, Green, Beatty, \& Thompson, 1967) electric shock (e.g., Lints \& Harvey, 1969) and heat (Wakeman, Donovick, \& Burright, 1970) as well as to 
agents such as water, sucrose, and food which are customarily employed as positive reinforcers. Because the alteration in reactivity to stimuli is so ubiquitous following septal lesions, it is not surprising that the importance of a change in one factor, e.g., the quality of the reinforcer, varies from one situation to another. We agree with Fallon and Donovick (1970, p. 155) that "Septal lesions... appear to enhance the response to the immediate cues guiding the response." However, it should be emphasized that the immediate cues will vary from task to task and quite possibly from moment to moment within a particular task. Since the typical behavioral test situation is designed to limit the number of stimuli to which the animal responds, the behavior of animals with septal lesions often appears "perseverative" with respect to a certain class of stimuli. However, if other stimuli are introduced into the situation which capture the animal's attention, the original perseverative deficit may disappear. For example, consider the dramatic improvement in the DRL performance of rats with septal lesions where wood blocks are introduced into the test environment (Slonaker \& Hothersall, 1972), or the absence of a deficit in spontaneous alternation in rats with septal lesions when visual and olfactory cues are placed in opposition (Thomas, 1972). This analysis does not deny that septal lesions may alter the animal's ability to utilize response-produced cues. Indeed, the greater behavioral control exercised by external stimuli may be in part a product of an altered ability to process proprioceptive information. The point is that in any behavioral test there are a variety of stimuli competing for the animal's attention. The behavior of animals with septal lesions appears more completely bound by the predominant stimuli of the moment, but these stimuli vary dynamically.

\section{REFERENCE NOTES}

1. Carlson, N. R., Standish, L. J., \& El-Wakil, F. Modification of septal DRL deficit in mice produced by reduction of incentive value of food reinforcement. Paper read at the Meeting of the Psychonomic Society, Boston, 1974.

2. Chin, T., Donovick, P. J., \& Burright, R. G. Septal lesions and learning deficits: Fact or fiction? Paper read at the Meeting of the Psy chonomic Society, Boston, 1974.

\section{REFERENCES}

Beatty, W. W., Beatty, P. A., O'Briant, D. A., Gregoire, K. C., \& Dahi, B. L. Factors underlying deficient passive avoidance behavior by rats with septal lesions. Journal of Comparative and Physiological Psychology, 1973, 85, 502-514.

Beatty, W. W., \& Schwartzbaum, J. S. Consummatory behavior for sucrose following septal lesions in the rat. Journal of Comparative and Physiological Psy chology, 1968, 65, 93-102.

Braggio, J. T., \& Ellen, P. Differential proprioceptive feedback and DRL performance of normal and septal rats. Journal of Comparative and Phy siological Psychology, 1974, 87, 80-90.

Caplan, M., \& Stamm, J. S. DRL acquisition in rats with septal lesions. Psy chonomic Science, 1967, 8, 5-6.

Donovick, P. J. Effects of localized septal lesions on hippocampal EEG activity and behavior in rats. Journal of Comparative and Physiological Psychology, 1968, 66, 569-578.
Ellen, P., \& Butter, J. External cue control of DRL performance in rats with septal lesions. Physiology and Behavior, 1969, 4, 1-6.

Ellen, P., Wilson, A. S., \& Powell, E. W. Septal inhibition and timing behavior in the rat. Experimental Neurology, 1964, 10, 120-132.

Fallon, D., \& Donovick, P. J. Low resistance to extinction in rats with septal lesions under inappropriate incentive motivation. Journal of Comparative and Physiological Psychology, 1970, 73, 150-156.

Fried, P. A. Septum and behavior: A review. Psychological Bulletin, 1972, 78, 292-310.

Gittelson, P. L., \& Donovick, P. J. The effects of septal lesions on the learning and reversal of a kinesthetic discrimination. Psy chonomic Science, 1968, 13, 137-138.

Gittelson, P. L., Donovick, P. J., \& Burright, R. G. Facilitation of passive avoidance acquisition in rats with septal lesions. Psychonomic Science, 1969, 17, 292-293.

Gomer, F. E., \& Goldstein, R. Attentional rigidity during exploratory and simultaneous discrimination behavior in septal lesioned rats. Physiology and Behavior, 1974, 12, 19-28.

Hamilton, L. W., Kelsey, J. E., \& Grossman, S. P. Variations in behavioral inhibition following different septal lesions in rats. Journal of Comparative and Physiological Psy chology, 1970, 70, 79-86.

Harvey, J. A., \& Hunt, H. F. Effect of septal lesions on thirst in the rat as indicated by water consumption and operant responding for water reward. Journal of Comparative and Phy siological Psy chology, 1965, 59, 49-56.

Hothersall, D., Johnson, D. A., \& Colleen, A. Fixed ratio responding of normal and septal rats. Journal of Comparative and Physiological Psychology, 1970, 73, 470-476.

Kelsey, J. E., \& Grossman, S. P. Nonperseverative disruption of behavioral inhibition following septal lesions in rats. Journal of Comparative and Physiological Psychology, 1971, 75, 302-311.

Lints, C. E., \& Harvey, J. A. Altered sensitivity to footshock and decreased brain serotonin following brain lesions in the rat. Journal of Comparative and Physiological Psychology, 1969, 67, 23-32.

McCleary, R. A. Response specificity in the behavioral effects of limbic system lesions in the cat. Journal of Comparative and Phy siological Psy chology, 1961, 54, 605-613.

Neill, D. B., Ross, J. F., \& Grossman, S. P. Comparison of the effects of frontal, striatal, and septal lesions in paradigms thought to measure incentive motivation or behavioral inhibition. Phy siology and Behavior, 1974, 13, 297-306.

Schwartzbaum, J. S. \& Donovick, P. J. Discrimination reversal and spatial alternation associated with septal and caudate dysfunction in rats. Journal of Comparative and Phy siological Psy chology, 1968, 65. 83-92.

Schwartzbaum, J. S., Green, R. H., Beatty, W. W., and Thompson, J. B. Acquisition of avoidance behavior following septal lesions in the rat. Journal of Comparative and Physiological Psy chology, 1967, 63, 95-104.

Schwartzbaum, J. S., Kellicutt, M. H., Spieth, T. M., \& Thompson, J. B. Effects of septal lesions on response inhibition associated with food reinforced behavior. Journal of Comparative and Physiological Psychology, 1964, 58, 217-224.

Slonaker, R. L., \& Hothersall, D. Collateral behaviors and the DRL deficit of rats with septal lesions. Journal of Comparative and Phy siological Psychology, 1972, 80, 91-96.

Slotnick, B. M., \& Jarvik, M. Deficits in passive avoidance and fear conditioning in mice with septal lesions. Science, 1966 , $154,1207-1208$.

Srebro, B. Visual cues in successive position reversals: Retention deficits following septal lesions. Physiology and Behavior, $1974,12,639-646$.

Srebro, B., \& Divac, I. Successive position reversals in rats with septal and/or fronto-polar lesions. Physiology and Behavior, 1972, 9, 269-272.

Thomas, J. B. Stimulus perseveration and choice behavior in rats with septal lesions. Journal of Comparative and Phy siological Psy chology, 1972, 80, 97-105.

Wakeman, K A Donovick, P. J \& Burright, R. G. Septal lesions increase bar pressing for heat in animals maintained in the cold. Physiology and Behavior, 1970, 5, 1193-1195.

(Received for publication December 5, 1974; revision accepted February 15, 1975.) 